\title{
Erratum
}

\section{K-Vacancy Formation in Deep Inelastic Nuclear Reactions}

U. Müller, J. Reinhardt, G. Soff, B. Müller, and W. Greiner

Z. Phys. A - Atoms and Nuclei 297, 357-358 (1980)

The values of $P(T)$ for the $2 p \sigma$-level in $\mathrm{Xe}-\mathrm{Pb}$

(upper curve in Fig. 2) have to be reduced by a factor 4 .

U. Müller

J. Reinhardt

G. Soff

B. Müller

W. Greiner

Institut für Theoretische Physik

Johann-Wolfgang-Goethe-Universität

Robert-Mayer-Straße 8-10

D-6000 Frankfurt/Main 1

Federal Republic of Germany 